\title{
INFORMACIÓN BIBLIOGRÁFICA
}

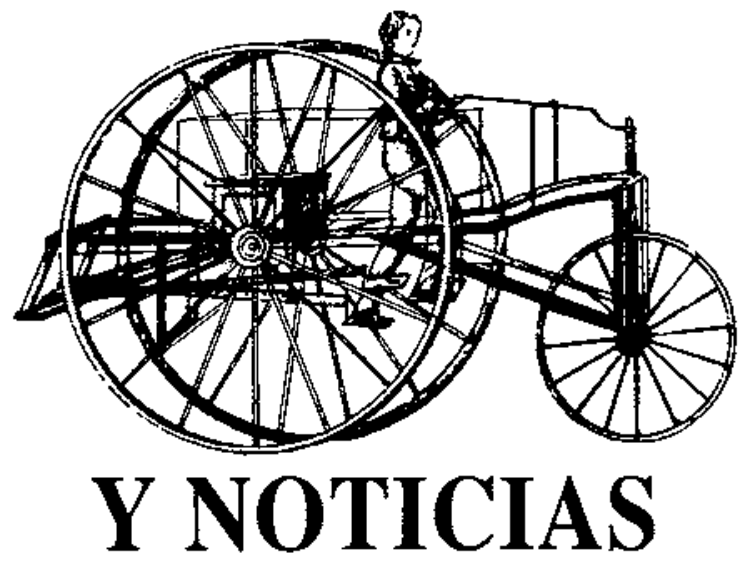

\section{TESIS DIDÁCTICAS*}

\begin{abstract}
* Recordamos que los datos que se precisan para la publicación de los resúmenes de tesis didácticas son los siguientes: Título; autor o autora; tipo de tesis (doctoralo de maestría); director(es) o directora(s); departamento, universidad, programa en que se ha presentado; fecha de presentación; resumen de un máximo de dos folios DIN A-4 acompañado de disquete.
\end{abstract}

PROCESOS DE APRENDIZAJE EN MATEMÁTICAS CON POBLACIONES DE FRACASO ESCOLAR EN CONTEXTOS DE EXCLUSIÓN SOCIAL. LAS INFLUENCIAS AFECTIVAS EN EL CONOCIMIENTO DE LAS MATEMÁTYCAS

\section{Tesis doctoral}

Autora: Gómez Chacón, Inés $M$. Director: De la Orden Hoz, Arturo Lugar: Facultad de Educación. Departamento de Métodos de Investigación y Diagnóstico en Educación. Universidad Complutense

Fecha: 11 de septiembre de 1997

La finalidad de esta tesis es detcrminar y describir la dinámica de interacción entre Ios factores cognitivos y afectivos en el aprendizaje de la matemática con po- blaciones de fracaso escolar en contextos de exclusión social. El trabajo se inscribe en el marco de la investigación didáctica en el área de la psicología y sociología en Educación Matemática.

Los aspectos que nos parecen más relevantes con relación al estudio realizado son:

- la oportunidad del tema, en un momento en el que las tendencias en la investigación de la enseñanza y aprendizaje de Ia matemática tienen como características el interés creciente por los aspectos relacionados con la dimensión afectiva del individuo y el contexto sociocultural del aprendizaje;

- el contexto de estudio del problema;

- Ios aspectos metodológicos;

- la teoría fundamentada por Ios datos, término acuñado por Glaser y Strauss, que hemos denominado teoria emergente.
En relación con el tema de la dimensión afectiva, la comunidad científica ha puesto de relieve en numerosas ocasiones la necesidad de articular, en las investigaciones sobre afecto, dos descriptores específicos del dominio afectivo: la emoción $y$ las creencias. En el estudio se han tratado estos dos descriptores, rastreando las reacciones afectivas desde las creencias que las originan. También se ba puesto de relieve la necesidad de prestar atención a las investigaciones que tratan la interacción cognición y afecto, así como el papel de esta interacción en los procesos cognitivos. Y, por último, se ha tratado de configurar un marco teórico para trabajar la dimension afectiva en matemáticas.

En cuanto al enfoque del aprendizaje desde una perspectiva sociocultural, en el trabajo se destaca lo referente a las implicaciones para la instrucción y la aproximación a la emoción desde esta perspectiva, ya que las investigaciones en afecto han estado separadas de 
los estudios sobre aprendizaje en contexto.

Otra aportación que nos parece original dada la escasez de investigaciones en este ámbito y relativas a esta poblaciónes la del contexto de estudio del problema: un contexto de exclusión social y en poblaciones de fracaso escolar -el estudio principal se ha realizado con un grupo de 23 jóvenes, en el taller de ebanistería de un centro-taller-. El trabajo pretende elaborar una propuesta alternativa de educación y proponer algunas posibles estrategias de erradicación.

En cuanto a los aspectos metodológicos: se ha tratado de conocer e interpretar el significado de algunos fenómenos que ocurren en situaciones de aprendizaje desde el punto de vista de los sujetos implicados.

En relación con la estrategia de investigación utilizada, se ha elaborado un diseño en el que se combinan las técnicas propias de la etnografía con las del estudio de casos, así como la reflexión sobre la propia acción. Para cubrir el objetivo de la investígación se llevaron a cabo dos estudios interdependientes de carácter etnográfico: uno exploratorio y otro principal.

Los instrumentos de recogida de datos diseñados expresamente para este trabajo han resultado ser una aportación determinante para el mismo dada la escasez y falta de adecuación de instrumentos de recogida de datos sobre la dimensión afectiva del individuo para poblaciones semejantes a la del estudio. De ellos destacamos el Mapa de Humor de los problemas (instrumento de diagnóstico de las reacciones emocionales y de autorregulación de la emoción); las entrevistas sobre situaciones (para recoger datos sobre el sistema de creencias y valores asociado con el conocimiento matemático escolar y sobre el conocimiento matemático en la práctica y en un contexto de desventaja social); y el programa de actuación didáctica (desarrollo de módulos de aprendizaje orientados a la práctica escolar que integren la dimensión afectiva y el contexto cultural de la práctica).

Por último, destacariamos la teoría «fundamentada' por los datos según el término acuñado por Glaser y Strauss, que se denomina en el presente trabajo teoría emergente. La teoría «emergente» de los datos ha puesto de manifiesto la necesidad de un marco teórico comprensivo de la dimensión afectiva desde un perspectiva holística. Y esta perspectiva ha permitido el diseño de lo que denominamos un modelo de afecto global: la articulación de las teorías cognitiva y las teorías socioculturales, desde la que establecer un marco comprensivo de la dimensión afectiva en matemáticas. Se han definido diferentes constructos para ia operativización didáctica de la dimensión afectiva: afecto local, afecto globat, metaafecto.

La realización del estudio de casos no se ha centrado sólo en uescenarios simples» (reacciones emocionales en fases concretas de resolución de problemas, errores, etc.), sino en «escenarios complejos», que tienen en cuenta a la persona en situación, ya que las reacciones afectivas consiguen su carăcter cualitativo si son contextualizadas en la realidad social que las produce.

Para cada sujeto del estudio de casos se han catalogado sus tendencias cognitivas y afectivas, llegándose a elaborar el Mapa Afecto-Cognición, síntesis de las anotaciones del alumno y de las observaciones de la investigadora. En este mapa queda reflejada la estructura local y global del afecto expresada a través de las emociones consensuadas en el mapa de humor y las rutas de interacción con los procesos cognitivos (exigencias cognitivas).

La aproximación mediante escenarios simples nos ha llevado a una serie de conclusiones, de las que destacamos las siguientes:

En el estudio de casos se pudo constatar que existen tendencias y perfiles que permiten delimitar las características del afecto global del sujeto. Los datos del estudio de casos apuntan dos rutas que implican el afecto y la cognición, una que podríamos llamar positiva y otra negativa; a través de ellas se ha podido delimitar un «modelo» para el sujeto. Se ha podido constatar que, entre las características que comparten la dimensión local del afecto de cada individuo, aparecían reiteradas formas de reaccionar ante la matemática y su aprendizaje; coincidencias en su visión de la matemática; miedos inseguridades, evocaciones de la experiencia escolar, etc.

Sin embargo se observa que las evoluciones de los sujetos eran diferentes. Tras aparentes coincidencias en la interrelación cognición y afecto se daba una fuerte diferencia y ésta estaba estrechamente ligada a sus posicionamientos como miembros de un grupo social, que configura su afecto global y que está incidiendo en el afecto local. Por tanto, se debería tener en cuenta la dimensión afectiva del individuo en escenarios más complejos

La identidad social de los jóvenes contribuye a configurar, por su carácter relacional y dinámico, la estructura local y global del afecto; es decir, incide en las rutas del afecto local que se establecen con el sistema cognitivo y contribuyen a Ia construcción de estructuras generales del concepto de uno mismo, y a la formación de creencias acerca de la matemática y de su aprendizaje

Los datos ponen de manifiesto que los estudiantes reciben continuos mensajes del entorno sobre qué significa conocer matemáticas y cuál es el significado social de su aprendizaje. La estructura de autoconcepto como aprendiz de matemáticas está relacionada con sus actitudes, con la perspectiva en que sitúa el mundo matemático y con su identidad social.

La inclusión de la perspectiva de la identidad social acentúa la necesidad de considerar la influencia de las relaciones simbólicas sociales. Es en este nivel donde hemos tratado de comprender cómo las valoraciones, a las cuales los grupos sociales ligan las diferentes formas de conocimiento, son mediadoras en la cognición matemática. La atención a este aspecto nos ha proporcionado datos para construir una interpretación global de afecto en cada sujeto.

\section{BASES PARA UNA PROPUESTA DIDÁCTICA SOBRE INTEGRALES}

\section{Tesis de maestría}

Autora: Calvo Pesce, Cecilia Directora: Azcárate, Carmen

Lugar: Departament de Didàctica de la Matemàtica i les Ciències Experimentals. Facultat de Ciències de l'Educació Universitat Autònoma de Barcelona Fecha: septiembre de 1997

Esta tesis consiste en una serie de estudios que comparten la fínalidad de obtener algunas pautas a partir de las cuales se pueda elaborar una propuesta didáctica acerca de integrales dirigida a alumnos de un primer curso de cálculo. El primero de estos estudios se centra en el pensamiento matemático avanzado, 10 que permite reformular el objetivo de la tesis en términos de la búsqueda de bases para la construcción, por parte del alumno, de un esquema conceptual de inte- 
gral coherente con su definición formal y rico en relaciones con los esquemas conceptuales de área y derivada. Los restantes estudios presentados en esta tesis corresponden a: una revisión de propuestas didácticas sobre integrales y sobre áreas de regiones no poligonales, el análisis de diferentes acercamientos al Teorema Fundamental del cálculo y un estudio experimental donde se recoge información acerca de cómo acotan, calculan y aproximan, los alumnos de dos grupos de COU, Ias áreas de regiones dadas en el contexto de gráficos de funciones y fuera de él.

Para la formación de un esquema conceptual coherente y compatible con el que comparte la comunidad matemática, no es indiferente la elección de la definición que se presente del concepto, como tampoco lo es la elección de los ejemplos y contraejemplos que la acompañan, las imágenes visuales que se sugieren o los problemas de aplicación que se proponen. Ante la firme creencia de que la integración es mucho más que la operación inversa de la derivación, y tomando en consideración el desarrollo historico del cálcuio integral y los cursos de cálculo con que se pueden encontrar estos alumnos en el futuro, se propone como definición de integral una versión resultante de transponer didácticamente Ia definición de Riemann formulada en términos de supremos de sumas inferiorese ínfimos de sumas superiores.

El tratamiento de cotas superiores e inferiores debería ocupar un lugar importante en la secuencia didáctica preparatoria de esta definición de integral. Dicha secuencia debería tomar en cuenta las conclusiones a que se ha llegado en la parte experimental de este trabajo respecto a las relaciones entre las actividades de aproximación y acotación y a las diferencias en el tratamiento de cotas superiores einferiores. Entre estas conclusiones se pueden destacar dos: a) la primera, relacionada con el uso reiterado, por parte de algunos de los alumnos encuestados, del argumento

«a $\alpha \alpha$ entonces $\alpha-\varepsilon<a<\alpha+\varepsilon »$,

lo cual evidencia una confusión entre el papel de los datos aproximados y el de los datos suministrados por cotas, que se constató que trasciende el contexto del cálculo de áreas; $b$ ) la segunda, relacionada con la constatación de una tendencia a acotar superiormente con mayor facilidad que inferiormente, así como una mayor frecuencia del uso de argumentos de discutible validez en el momento de acotar inferiormente en comparación con las instancias de justificación de cotas superiores. Frente a estos hallazgos de la parte experimental, el análisis de distintas propuestas didácticas de acercamiento al concepto de integral y al concepto de área de figuras no rectilineamente determinadas permitió sugerir la inclusión de determinadas actividades en la secuencia didáctica preparatoria a la definición de integral mediante sumas de Riemann.

Se decidió estudiar la posibilidad de fomentar las conexiones entre los esquemas conceptuales de integral y area, debido a que la noción de área representó el problema desencadenanté en el desarrollo histórico del concepto de integral, a que es una noción que los alumnos manejan desde antes y que permite ser retomada para recrear el mencionado problema desencadenante y porque brinda imágenes visuales de integral que enriquecen el esquema conceptual del alumno. Estas imágenes no pueden de. jarse de lado en el momento de sugerir propiedades ni restringirse al nivel heurístico, sino que deberían particjpar en el proceso de convencimiento de validez de esas propiedades. En este trabajo se buscó establecer enlaces entre las nociones de área e integral más allá de la ilustración de la definición de integral; para elio se estudió un acercamiento al Teorema Fundamental del cálculo totalmente impregnado del uso de la metáfora de la integral como área y se exploró un itinerario didáctico destinado a fomentar la formalización de la noción de área que guarda cierto paralelismo con la historia de formalización del concepto y que permite sentar las bases para un trabajo futuro con integrales y, también, generar imágenes visuales asociadas a la noción de integrabilidad en relación con la existencia de figuras del plano a las cuales no se asocia un área.

La asociación entre área bajo el gráfico e integral de una función positiva, aunque representa un importantísimo recurso didáctico para la presentación del tema de integrales, debe ser tratado con cuidado, ya que un desborde del campo de aplicación de esta asociación lleva a abusos que trascienden el lenguaje, convirtiéndose en un obstáculo didáctico importante.
Para incentivar la creación de lazos entre el esquema conceptual de integral y el de derivada se trabajó detenidamente en torno al Teorema Fundamental del cálculo. Aunque la propuesta central de acercamiento a este teorema se desarrolió a partir de la demostración dada por Barrow -seleccionada por su sabor geométrico al revelar la relación entre integral y derivada relacionando áreas con tangentes - también se repasaron otros acercamientos a este teorema. Los acercamientos a que se hace referencia no representan demostraciones rigurosas, sin embargo se los considera valiosos puntos de partida en la búsqueda de justificación, comunicación y explicación de la relación entre integral y derivada.

En un principio, el objetivo de incluir en este trabajo una reflexión sobre el pape: de la demostración, tanto en la comunidad matemática como en el aula, era la justificación de la búsqueda de demostraciones alternativas del teorema fundamental del cálculoque explicaran la telación entre integral y derivada mostrando y usando las ideas matemáticas que to motivaron. Después de analizar los datos recogidos en la parte experimental, la alta frecuencia detectada en el uso de argumentos visuales poco convincentes reforzó la relevancia de esta reflexión. No se puede descuidar la importancia de convencer al alumno de la necesidad de una cuidadosa presentación de argumentos que permita que éstos sean examinados por la comunidad, para lo cual es necesario involucrar un cierto grado de formalización.

Quedan pendientes algunas cuestiones que serán retomadas en un próximo trabajo. Algunas de estas cuestiones aparecieron recientemente, después del análisis de los datos recogidos en la parte experimental de este trabajo, entre ellas se destacan los interrogantes que quedan planteados acerca de la influencia del currículo en la confusión detectada entre las actividades de acotación y aproximación, la búsqueda de razones que expliquen las diferencias en el tratamiento de cotas superiores e inferiores observadas entre los estudiantes de esta muestra y la necesidad de profundizar en una discusión acerca de qué tipo de argumentos visuales se consideran convincentes en el momento de justificar propiedades matemáticas en el auja. 